\title{
PREFA CE
}

In connection with arranging IAU Symposium No. 50 on 'Spectral Classification and Multicolour Photometry', sponsored by Commissions 45 and 25, it was decided to exclude all calibration problems. Instead it was agreed that we should attempt to arrange a separate symposium, dealing with the fundamental problems of the calibration of absolute magnitudes and temperatures of stars.

The Executive Committee of the IAU accepted our proposal, and IAU Symposium No. 54 was held in Geneva on September 12-15, 1972, sponsored by the following IAU Commissions: $24,25,29,33,35,37,44$ and 45. It was attended by about 90 scientists representing 16 countries.

The Symposium was divided into eight sessions. Each session started with a review paper by an invited speaker; this was followed by a general discussion including a few contributed papers.

The contents of the present volume follow closely the programmes of the individual sessions of the Symposium. Most of the recorded discussions have been kept, and only in a few cases have the order of questions and comments been altered so as to obtain more homogeneity in the presentation.

Financial assistance was provided by the Executive Committee of the International Astronomical Union for travel grants to certain participants. Some travel grants were also supplied by the 'Fonds national suisse de la recherche scientifique'. We are grateful to the Universities of Geneva and Lausanne for additional support such as secretarial help and other facilities. Mrs M. Zuger and Miss B. Zwenzner are gratefully acknowledged for their assistance at all stages of preparation of the present volume. 